\title{
Interfascicular neurolysis in chronic ulnar nerve lesions at the elbow: an electrophysiological study
}

\author{
VIGGO KAMP NIELSEN, OLE OSGAARD AND WERNER TROJABORG \\ From the I.aboratory of Clinical Neurophysiology and the Department of Neurosurgery, University Hospital \\ (Rigshospitalet), Copenhagen
}

SUMMARY Interfascicular neurolysis of the ulnar nerve at the elbow was performed in nine consecutive patients with moderate to severe ulnar palsy. Sensory and motor conduction velocities were determined before and up to six times after the operation, with a follow-up period of three years or more in all but two patients. None of the patients recovered after the operation, and all developed severe and sometimes persistent paraesthersiae. Electrophysiologically there was no evidence of improvement immediately following the operation. On the contrary in some patients there were changes suggesting deterioration. At the final investigation most electrophysiological parameters were still abnormal. The only significant change was an increase in the amplitude of sensory action potentials at the wrist and just below the elbow. Only one patient showed a more synchronised sensory potential after operation. It is our conclusion that interfascicular neurolysis of the ulnar nerve should be abandoned.

Surgical treatment of ulnar nerve palsies at the elbow is still a matter of dispute as many cases show considerable spontaneous improvement, both clinically and electrophysiologically. ${ }^{1}$ In severe cases, especially those with X-ray abnormalities of the ulnar groove, the common approach is antepositioning of the nerve, median epicondylectomy, or simple division of the tendinous insertion of the flexor carpi ulnaris muscle.

Common to most chronic ulnar nerve lesions in the elbow region is the development of epifibrosis and perifibrosis resulting in the formation of so-called pseudoneuroma, which may increase the likelihood of nerve entrapment. The application of microsurgical techniques in nerve repair has led to the introduction of interfasicular neurolysis by which fibrous tissue around the fascicles is removed. This is mostly used prior to fascicular nerve suturing in reconstructive nerve surgery. ${ }^{23}$ Interfascicular neurolysis has been recommended as a treatment of ulnar nerve palsies. ${ }^{4-9}$

As these reports are of a preliminary character, the study here presented deals with

Address for reprint requests: $\mathrm{Dr} \mathrm{W}$ Trojaborg, Laboratory of Clinical Neurophysiology, Rigshospitalet, DK 2100 Blegdamsvej 9, Copenhagen, Denmark.

Accepted 24 October 1979 detailed clinical and electrophysiological findings before and after interfascicular neurolysis in nine consecutive patients with chronic ulnar palsy, followed up to $4 \frac{1}{2}$ years after surgical intervention.

\section{Patients and methods}

Two females and seven males, 21 to 68 years of age, had symptoms and signs of an advanced ulnar palsy, graded as severe in seven and moderate in two patients according to McGowan. ${ }^{10}$ Table 1 summarises clinical data on admission. Case 7 first developed a right-sided and seven months later a left-sided ulnar palsy, graded as severe and mild respectively. Electrophysiologically the nerves were about equally affected, and it was decided to operate on the right ulnar nerve only (referred to as case 7a (R)), leaving the left as control (case $7 \mathrm{~b}(\mathrm{~L})$ )).

Pathological findings during operation are shown in table 2. The sulcus was deformed by an old fracture in one, and was abnormally shallow in two patients. There was no narrowing of the cubital tunnel, but some nerves were encapsulated in a tube of hard fibrous epineurium. Two nerves appeared normal from the outside, the fibrous hypertrophy between fascicles only appearing after removal of the epineurium. Under the dissection microscope the single fascicles were seen to be surrounded by 
Table 1 Clinical findings in patients with chronic ulnar palsy

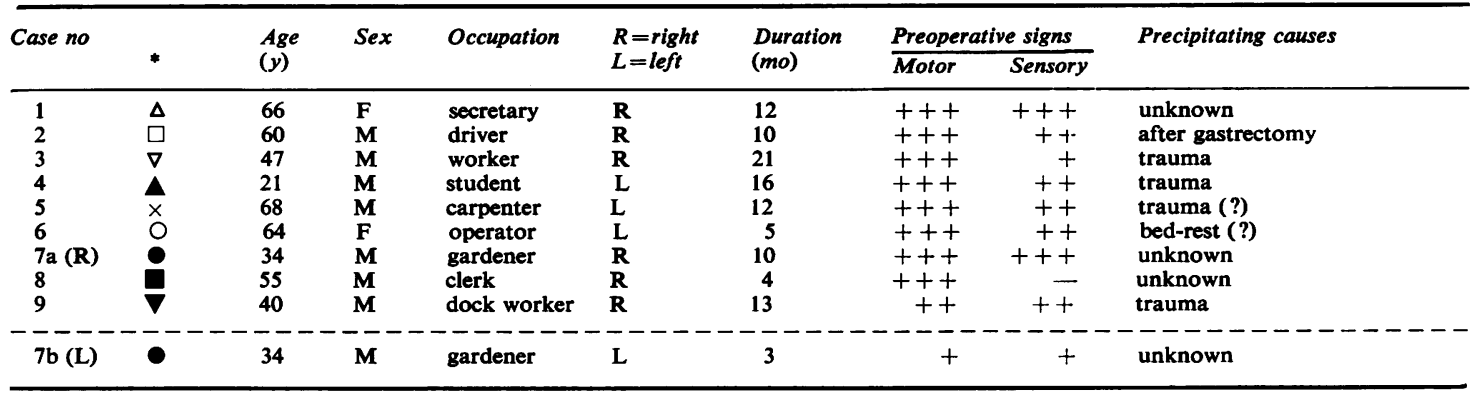

$+=$ slight, $++=$ moderate, $+++=$ severe. *Symbols refer to fig 2.

No $7 \mathrm{a}(R)$ and no $7 \mathrm{~b}(\mathrm{~L})$ are the same patient. The left ulnar nerve (7b (L)) was not operated upon.

Table 2 Pathological findings during interfascicular neurolysis of the ulnar nerve at elbow

\begin{tabular}{|c|c|c|c|c|c|c|}
\hline Case no & Sulcus & $\begin{array}{l}\text { Macroscopic } \\
\text { swelling }\end{array}$ & $\begin{array}{l}\text { Maximal } \\
\text { changes }\end{array}$ & $\begin{array}{l}\text { Epineurial } \\
\text { thickening }\end{array}$ & $\begin{array}{l}\text { Interfascicular } \\
\text { fibrosis }\end{array}$ & $\begin{array}{l}\text { Other } \\
\text { surgery }\end{array}$ \\
\hline $\begin{array}{l}1 \\
2 \\
3 \\
4 \\
5 \\
6 \\
7 a(R) \\
8 \\
9\end{array}$ & $\begin{array}{l}\text { normal } \\
\text { deep } \\
\text { normal } \\
\text { deformed } \\
\text { deep } \\
\text { shallow } \\
\text { shallow } \\
\text { normal } \\
\text { normal }\end{array}$ & $\begin{array}{l}+ \\
+ \\
\\
+ \\
+ \\
+ \\
+ \\
+\end{array}$ & $\begin{array}{l}\text { epicondyle } \\
\text { diffuse } \\
\text { distal sulcus } \\
\text { epicondyle } \\
\text { epicondyle } \\
\text { diffuse } \\
\text { epicondyle } \\
\text { distal sulcus } \\
\text { epicondyle }\end{array}$ & $\begin{array}{r}+ \\
++ \\
+ \\
+ \\
++ \\
+ \\
+++ \\
++ \\
+++\end{array}$ & $\begin{array}{r}+++ \\
+++ \\
+ \\
+++ \\
+++ \\
+++ \\
+++ \\
++ \\
+++\end{array}$ & $\begin{array}{l}\text { none } \\
\text { none } \\
\text { anteposition } \\
\text { anteposition } \\
\text { none } \\
\text { anteposition } \\
\text { anteposition } \\
\text { anteposition } \\
\text { anteposition }\end{array}$ \\
\hline
\end{tabular}

$+=$ slight, $++=$ moderate, $t++=$ severe.

massive condensed fibrous tissue, sometimes with a collar-shaped strangulation of the fascicle. By careful dissection the fascicles were freed from strangulating tissue (fig $1 \mathrm{a}$ and $1 \mathrm{~b}$ ). Two distinct groups could be identified during operation: 1: Normal looking fascicles where the fibrous tissue could easily be removed, 2 : very tiny fascicles not easily identified and looking grey and dim, making exact dissection very difficult. After neurolysis, six of the nerves were transposed anteriorly. Postoperatively, the patients were instructed how to avoid further compression of the nerve.

Electrophysiological examinations were made shortly before the operation, and one to six times after the operation. The observation period after surgery was three years or more except in two patients (case 5 and 9). An electromyogram (EMG) was performed in the abductor digiti minimi muscle (ADM) recording 1: the pattern and amplitude of the electrical activity at maximal effort, 2: the number of sites with fibrillation potentials and positive sharpwaves outside the end-plate zone (denervation activity), 3: the mean duration of at least 20 motor unit potentials sampled at random, and 4: the incidence of polyphasic potentials. The sensory and motor conduction velocity along the ulnar nerve was determined according to the method described by Payan. ${ }^{11-12}$ Sensory fibres were stimulated via ring electrodes around digit $\mathrm{V}$ and action potentials were picked up by needle electrodes, with the near nerve electrode placed close to the ulnar nerve at the wrist (w), below sulcus (bs) $5 \mathrm{~cm}$ distal to the medial epicondyle, and above sulcus (as) $5 \mathrm{~cm}$ proximal to the epicondyle. As the amplitude of the sensory action potential was below $2 \mu \mathrm{V}$ in all but one patient, electronic averaging of 256,512 , or 1024 traces were used. The degree of desynchronisation was evaluated from the temporal dispersion of all peaks that could be distinguished from base line noise. The evoked action potential was recorded in ADM between an $80 \mu$ stainless steel wire placed transversally through the belly of the muscle and a ring electrode placed around the distal phalanx of digit V. ${ }^{13}$

At postoperative examinations care was taken to use the same conduction distances as in the preoperative examination. During the examination the skin temperature of the arm was kept around $35^{\circ} \mathrm{C}$ by automatically regulated external heating. The electrophysiological findings were compared with those of normal controls matched for age. ${ }^{14}$ 


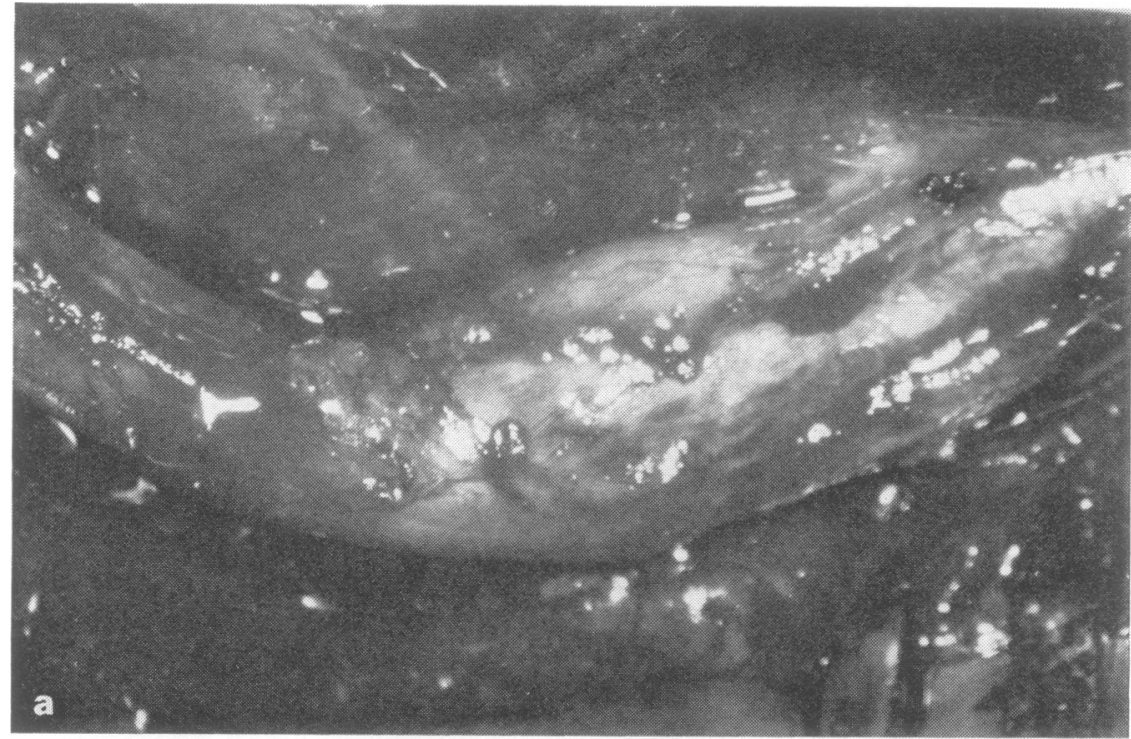

Fig la Ulnar nerve at the elbow before interfascicular neurolysis. Case $7 a$ $(R)$, male, 34 y.

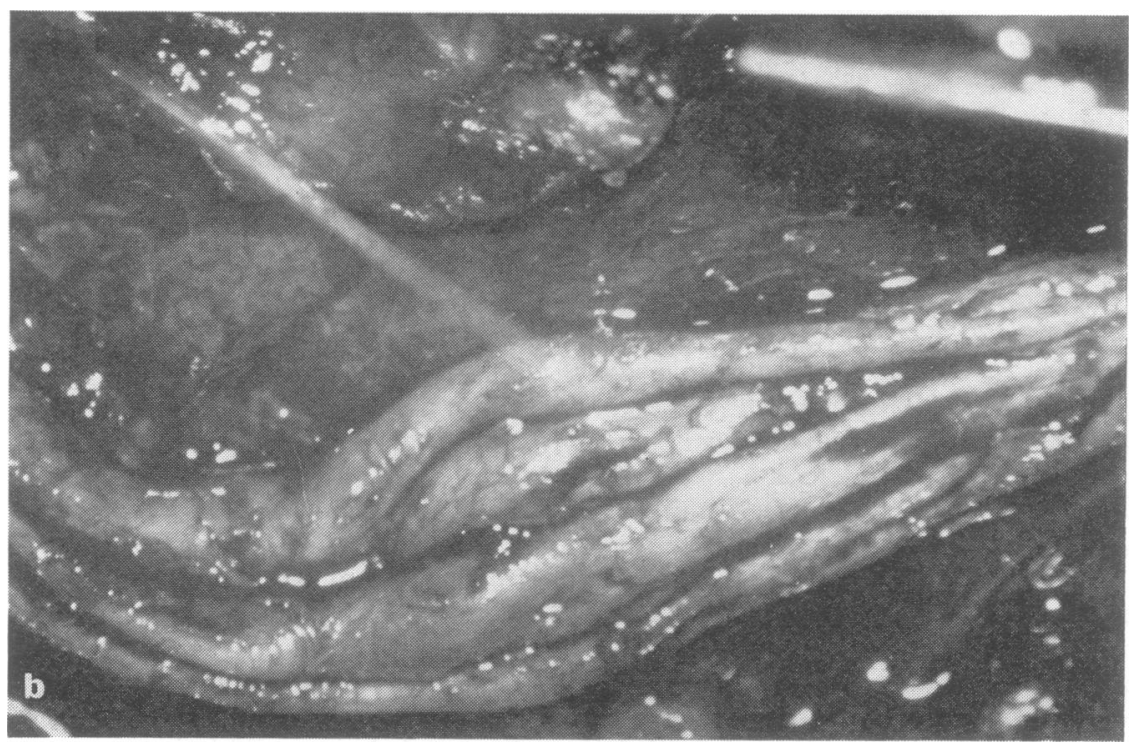

Fig 1b Same as fig la, after interfascicular neurolysis.

\section{Results}

1 CLINICAL FINDINGS

The preoperative clinical findings are described above (table 1). After the operation a temporary relief of symptoms was often reported, but this could not be verified by the clinical examination. Only case 1 regained some force in the hypothenar muscles. On the contrary, all patients complained of painful paraesthesiae irradiating distally from the elbow. In five of the patients the paraesthesiae were severe and persisted for many months, while in four patients they disappeared within a few months. In the latter group the nerve fascicles had a normal appearance under the operation microscope.

2 ELECTROMYOGRAPHY (table 3 )

Before the operation the EMG of the ADM showed widespread denervation activity, marked loss of motor units at maximal effort, an average increase of the mean potential duration of $52 \%$, and an average incidence of polyphasic potentials of $20 \%$. These findings are compatible 
Table 3 Electromyographic findings in $m$. abductor digiti minimi before and after interfascicular neurolysis of the ulnar nerve at elbow

\begin{tabular}{|c|c|c|c|c|c|c|c|c|}
\hline Case no & $\begin{array}{l}\text { Before or } \\
\text { after }\end{array}$ & Month & $\begin{array}{l}\text { Maxima } \\
\text { pattern* }\end{array}$ & $\begin{array}{l}\text { effort } \\
\qquad \text { ampl }(m V)\end{array}$ & $\begin{array}{l}\text { Fibrillation activity } \\
\text { number of sites }\end{array}$ & $\begin{array}{l}\text { Pote } \\
\text { ms }\end{array}$ & $\begin{array}{l}\text { al duration } \\
\% \text { deviation }\end{array}$ & $\begin{array}{l}\text { Polyphasia } \\
\% \text { of potentials }\end{array}$ \\
\hline \multirow[t]{2}{*}{1} & before & -1 & DA & 3.0 & 8 & $16 \cdot 1$ & +70 & 35 \\
\hline & after & 13 & DA & $2 \cdot 5$ & 4 & $16 \cdot 5$ & +74 & 21 \\
\hline \multirow[t]{2}{*}{2} & before & -3 & DA & 3.0 & 5 & 13.6 & +43 & 10 \\
\hline & after & 10 & RR & 7.0 & 0 & $12 \cdot 7$ & +34 & 19 \\
\hline \multirow[t]{2}{*}{3} & before & -3 & DA & 6.0 & 6 & $17 \cdot 3$ & $\begin{array}{l}+84 \\
\end{array}$ & 22 \\
\hline & after & 5 & $\mathbf{R R}$ & $4 \cdot 5$ & 3 & $15 \cdot 8$ & $\begin{array}{r}+69 \\
\end{array}$ & 18 \\
\hline \multirow[t]{2}{*}{4} & before & -2 & DA & 0.5 & 10 & 15.9 & +72 & 18 \\
\hline & after & 12 & RR & 2.0 & 4 & $11 \cdot 6$ & +26 & 36 \\
\hline 5 & before & -2 & DA & 9.0 & 5 & $13 \cdot 4$ & +41 & 8 \\
\hline \multirow[t]{2}{*}{6} & before & -1 & DA & 4.0 & 11 & $15 \cdot 6$ & +64 & 18 \\
\hline & after & 12 & RR & 3.0 & 0 & $10 \cdot 8$ & +14 & 20 \\
\hline \multirow[t]{2}{*}{$7 a(R)$} & before & -1 & DA & $3 \cdot 5$ & 6 & $14 \cdot 6$ & +57 & 15 \\
\hline & after & 12 & DA & 3.0 & 0 & $15 \cdot 2$ & +63 & 20 \\
\hline 8 & before & -1 & $\mathbf{R} \mathbf{R}$ & 3.0 & 0 & $10 \cdot 7$ & +14 & 0 \\
\hline \multirow[t]{2}{*}{9} & before & -1 & DA & $2 \cdot 0$ & 11 & $11 \cdot 8$ & +27 & 32 \\
\hline & after & 6 & DA & $7 \cdot 0$ & 0 & $11 \cdot 5$ & +24 & 33 \\
\hline
\end{tabular}

*DA $=$ discrete activity, $\mathbf{R R}=$ reduced recruitment, $F R=$ full recruitment.

with chronic partial denervation.

Seven patients were re-examined five to 13 months after the operation. Denervation activity was still present in three, but less pronounced. It had disappeared in four. The pattern at maximal effort was unchanged in three and slightly improved in four. A normalisation of the mean potential duration was seen in only one patient (case 6).

3 NERVE CONDUCTION STUDIES (table 4)

(a) Motor: Before the operation the motor con-

Table 4 Sensory and motor nerve conduction velocities and amplitude of evoked potentials in patients with ulnar palsy, before and after interfascicular neurolysis, during conservative treatment and in normal subjects

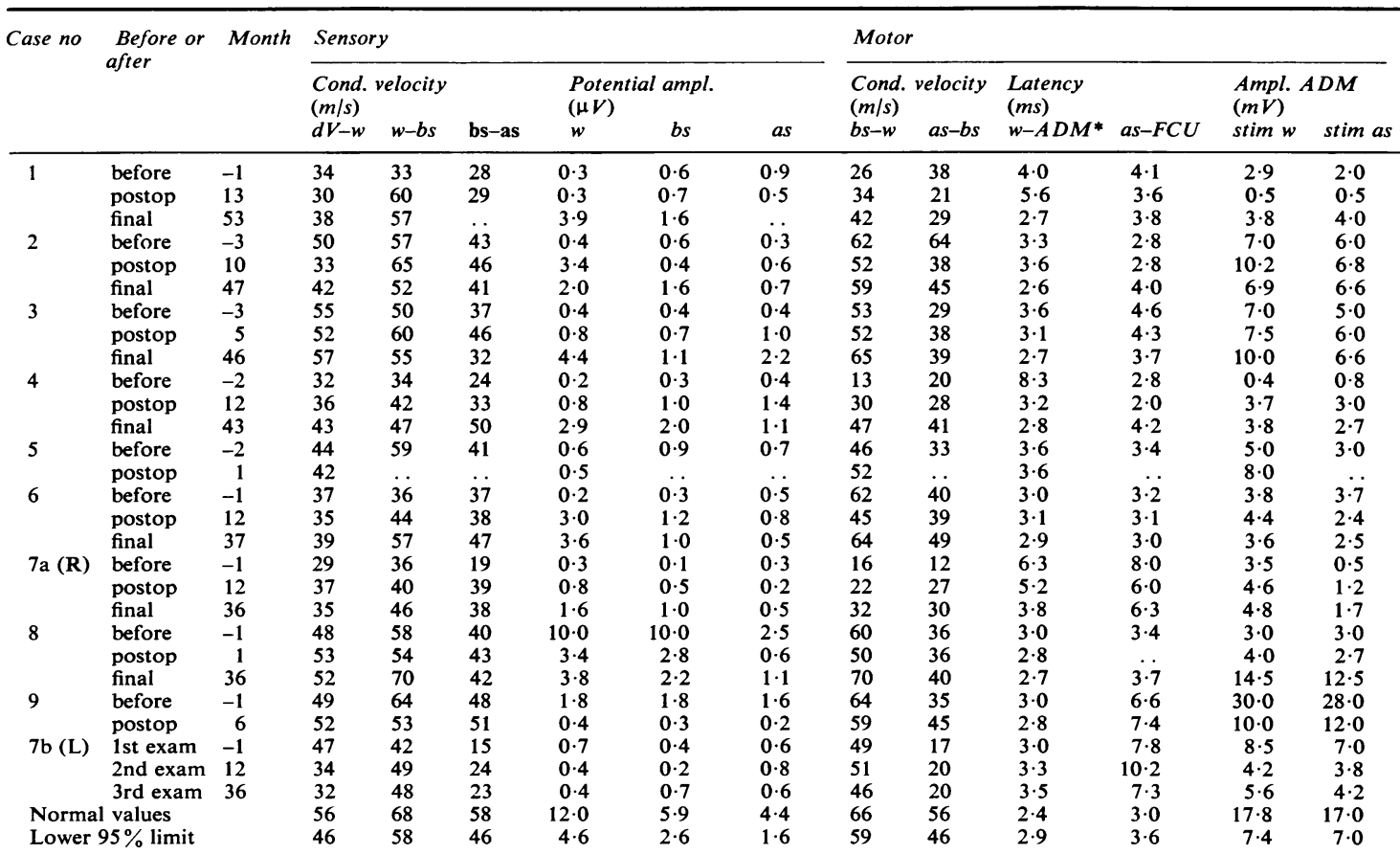

Abbreviations: $\mathrm{dV}=$ digit $\mathrm{V}, \mathrm{w}=$ wrist, $\mathrm{bs}=$ below sulcus, as = above sulcus, $\mathrm{ADM}=$ abductor digiti minimi muscle, $\mathrm{FCU}=$ flexor carpi ulnaris muscle. $*$ corrected to a standard distance of $70 \mathrm{~mm}$ (Slomic et al, 1968).26 
duction velocity was locally slowed across the elbow region in all but one patient (case 2), in whom there was a local slowing of the sensory conduction velocity. The latency to the flexor carpi ulnaris muscle was prolonged in four patients. In five patients the motor conduction was also slowed in the forearm segment distal to the ulnar groove. The amplitude of the muscle action potential (ADM) was below the $95 \%$ confidence limit in seven patients. In addition, four patients showed a reduction in amplitude of the ADM response on proximal stimulation, mild (30-40\%) in three and severe $(86 \%)$ in one, suggesting some degree of conduction block.

During the first year after the operation the conduction velocity across the elbow region was still slowed to about the same degree as before. In case 2 , moreover, in whom the preoperative velocity had been normal, motor conduction became significantly slowed after the operation. The conduction velocity in the forearm segment decreased significantly in three patients in whom it had been normal before operation. In the others there were no consistent changes. The amplitude of the response in ADM evoked at the wrist became normal in three, but was still well below normal in five cases. In case 9 the amplitude dropped from 30 to $10 \mathrm{mV}$. In four of the five patients without evidence of conduction block before operation the ADM response evoked above the sulcus postoperatively showed reduction in amplitude, indicating blocking of 20 to $45 \%$ of the motor fibres. In only one patient did a preoperative conduction block disappear after the operation.

At the final examination the conduction velocity was still slowed in the forearm segment and across the sulcus in five and six patients respectively. However, when compared with the examination one year after the operation five patients showed an increase of more than $10 \mathrm{~ms}$ in the forearm segment, and in two patients this was also seen in the segment across the sulcus. The longitudinal course is shown in fig 2. Finally, a substantial conduction block of motor fibres corresponding to the elbow region was still present in four patients.

(b) Sensory: Before the operation the sensory conduction velocity across the ulnar groove was moderately to severely slowed in all but one patient (case 9), in whom the ulnar nerve lesion could be localised to the elbow region by the slowing of the motor conduction in this segment, and by the increased latency to the flexor carpi ulnaris muscle. In addition, the sensory nerve

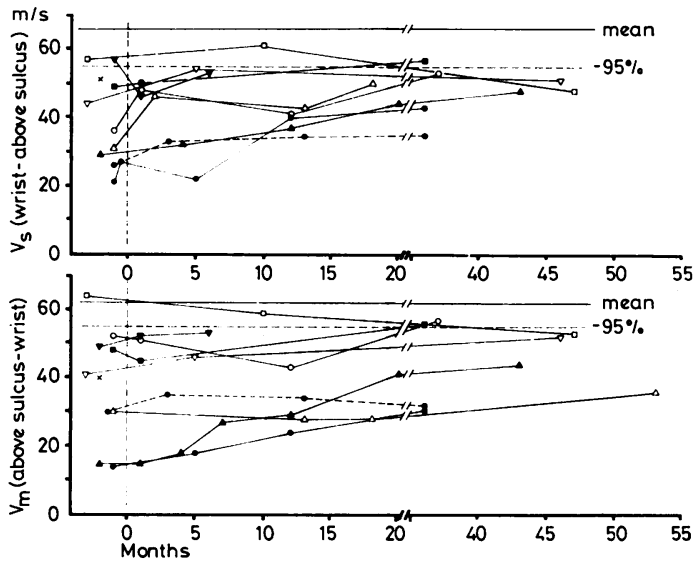

Fig 2 Above, sensory and below, motor conduction velocity along the ulnar nerve (wrist-above sulcus) before and after interfascicular neurolysis at elbow (vertical stippled line). The horizontal full and stippled lines indicate the normal mean value and the lower $95 \%$ confidence limit. Same symbols as in table 1. Filled circles connected by full and broken lines refer to the right (operated) and the left (non-operated) ulnar nerve respectively of case 7.

conduction was also slowed in the distal and forearm segment of the ulnar nerve in four patients and another two patients showed borderline values. The sensory potential amplitude was severely reduced $(<2 \mu \mathrm{V})$ in all but one patient (case 8), and the potentials were considerably desynchronised at all three levels of recording (wrist, below and above sulcus) (fig 3a).

After interfascicular neurolysis the sensory conduction velocities across the sulcus and in the forearm segment showed no consistent changes. In case 2 the distal sensory conduction velocity became clearly abnormal after the operation, remaining unchanged in the other patients. In case 7 the amplitude of the sensory potentials at the wrist, below and above sulcus remained essentially unchanged during the first postoperative year (fig $3 \mathrm{~b}$ ). The preoperative normal amplitudes in case 8 were actually smaller by about $60 \%$ after the operation, suggesting considerable fibre loss. With one exception the degree of desynchronisation was the same after as before the operation (fig $3 a$ and $3 \mathrm{~b})$. Only case 6 showed evidence of resynchronisation, as indicated by a decrease of the temporal dispersion of the individual potential components (fig 4).

At the final investigation after 3 to $4 \frac{1}{2}$ years 


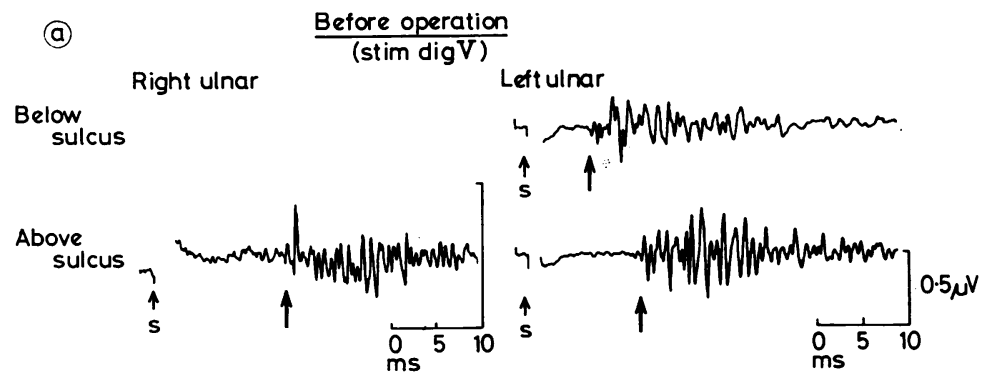

(b) After one year

Right ulnar (operated) Left ulnar (not operated)

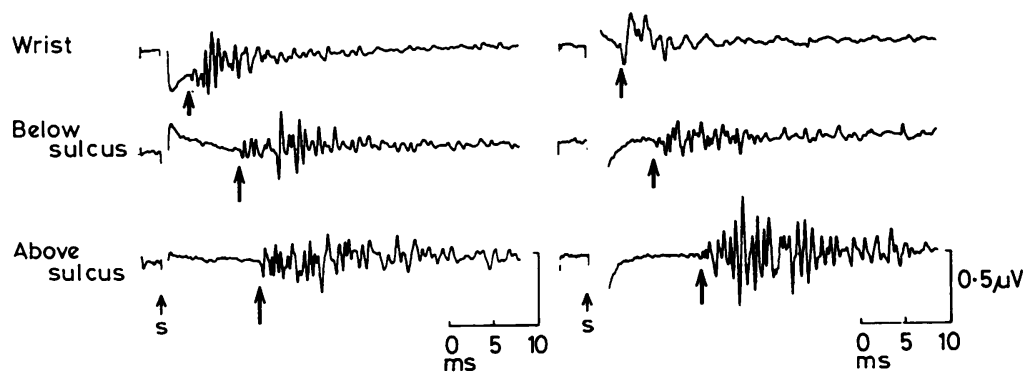

Fig 3a Sensory action potentials recorded from the right and left ulnar nerves following stimulation of the fifth digit in case 7 two weeks before interfascicular neurolysis of the right ulnar nerve. Due to a technical error the potential below the right ulnar groove (=sulcus) was not properly recorded. The thin arrow below each trace indicates the onset of the potential identified as it increased proportional with the calibration signal when 500 and 1000 responses were electronically averaged (not shown in the fig). The conduction velocity along the right and left forearm segment was 36 and $42 \mathrm{~ms}$ respectively compared with 19 and $15 \mathrm{~ms}$ in the elbow segment (below to above sulcus). $S=$ stimulus.

Fig $3 \mathrm{~b}$ Sensory potentials over right and left ulnar nerves (case 7) recorded at wrist, below and above the ulnar groove (=sulcus) 12 months after interfascicular neurolysis of the right ulnar nerve at elbow. Potentials are recorded by electronic averaging of 500-1000 stimuli. Distal conduction velocity (Dig $V-w$ ) along the right and left ulnar nerves was 37 and $34 \mathrm{~ms}$ respectively, along the forearm segment 40 and $49 \mathrm{~ms}$, and across the elbow region 39 and $24 \mathrm{~ms}$ respectively. ( $S=$ stimulus).

there was no significant improvement in the sensory conduction velocities (fig 2 ). The potential amplitudes were still severely reduced in all the seven patients reexamined, although in three the amplitude of action potentials recorded below the sulcus and at the wrist showed some improvement as compared with the values recorded one year after the operation. Potentials recorded above the sulcus showed no improvement in amplitude or degree of synchronisation.

\section{SPONTANEOUS COURSE}

On the nonoperated side in patient 7 (case $7 \mathrm{~b}$
(L)) the EMG of the ADM showed signs of chronic partial denervation. The site of the ulnar lesion was clearly localised to the elbow region by the severe slowing of motor and sensory conduction velocity "across" the sulcus (table 4), but there was no reduction of the muscle potential amplitude or signs of attenuation on proximal stimulation. The sensory potentials were considerably desynchronised, with a severe reduotion in the amplitude at all three levels of recording, similar to findings in the right ulnar nerve (fig 3a). These findings remained unchanged at the electrophysiological 


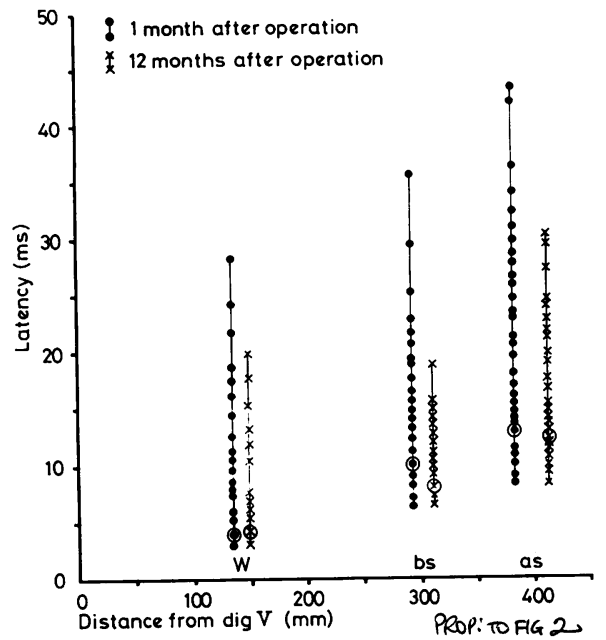

Fig 4 Latencies of the individual components of sensory potentials recorded at wrist, below and above the ulnar groove one and 12 months after interfascicular neurolysis respectively. The main component (highest peak-to-peak amplitude) is encircled. Note the decrease in the temporal dispersion 12 months after the operation. Case 6, 64 year old female.

examination one and three years later, there being thus no evidence of spontaneous recovery, but also no evidence that this nerve had fared conspicuously worse than that on the operated side. (fig 2 and $3 b$ ).

\section{Discussion}

Most of our patients had severe ulnar nerve palsies with a progressive course before the operation. Electrophysiologically, the severity was manifested by slowing of nerve conduction not only across the sulcus but also in distal sensory and motor segments of the nerve. In eight patients a sensory potential could only be detected using a signal averager, due to severe fibre loss. This was of particular importance in case 2 where the lesion could only be localised by the selective slowing of sensory conduction across the sulcus, possibly due to the topography of fascicles at the sulcus. ${ }^{15}$ The EMG of the hypothenar muscle indicated that the loss of motor fibres was equally severe, as a pattern of discrete activity at maximal effort was recorded in all but one patient. Thus, there was electrophysiological evidence of a pronounced regional segmental demyelination, with axonal block of several sensory and motor fibres at the elbow, while the sometimes severe slowing of nerve conduc- tion distal to the sulcus could indicate conduction along regenerated fibres.

Interfascicular neurolysis was not successfuí in restoring nerve function, both when used as the only method (cases $1,2,5$ ) and when used in combination with anterior transposition of the nerve. During the first year after the operation, the electrophysiological examinations were characterised by the deterioration of previously normal or near-normal nerve conduction parameters, indicating that these nerves had been subjected to further damage with a significant loss of motor and sensory fibres. In nerves already severely damaged there were no conspicuous signs of improvement, when the patients are considered as a group. Thus, only one patient (case 6) showed slight evidence of regeneration, indicated by a resynchronisation of the sensory potentials. Postoperative painful paraesthesia was a serious complication, not encountered after conventional anterior transposition; this occurred only when the nerve fascicles had been exposed under the operation microscope after the interfascicular neurolysis. A possible explanation for this adverse phenomenon could be that the nervi nervorum, which are known to transverse the perineurium and epineurium, ${ }^{16}$ had been cut during the neurolysis.

An improvement that can only be detected more than one year after the operation should probably not be ascribed to the operation per se, and in our opinion interfascicular neurolysis should not be credited with the moderate increase in motor conduction velocity or sensory potential amplitude seen in some patients at the final investigation compared with the examination one year after the operation. We observe that the final results obtained here are obviously poorer than those obtained in other studies, where anterior transposition was performed without neurolysis. ${ }^{12}{ }^{17}$ This would suggest that the possible benefit of anterior transposition in our patients may have been counteracted by the interfascicular neurolysis itself, due either to surgical trauma to the nerve, or, more likely, to exposure of the fascicles by removal of the supportive and protective epineurium.

The present study is not easily compared with others on interfascicular neurolysis. The published reports are either based on clinical evaluations, ${ }^{49}$ or the electrophysiological results appear as preliminary data. ${ }^{8}$ In the carpal tunnel syndrome division of the transverse carpal ligament combined with internal neurolysis resulted in a marked decrease of the distal motor latency within 30 minutes following surgery. ${ }^{5}$ However, 
the same observation was also made by Hongell and Mattsson ${ }^{18}$ following simple decompression without neurolysis. Elies and Driesen ${ }^{6}$ considered posttraumatic hypertrophy of neural connective tissue as an indication of "endoneurolysis" and found recovery in 21 of 28 operated cases. They could not, however, "establish any correlation between the electromyographical state and the clinical findings", and they did not comment on the possibility of spontaneous recovery. In contrast, several studies have established that clinical and electrophysiological improvement occurs following conventional anteposition of the ulnar nerve without interfascicular neurolysis even in patients with severe functional impairment and with macroscopic enlargement of the nerve comparable to that seen in our study. ${ }^{2117}{ }^{19}$ Similarly, clinical and electrophysiological recovery is well documented in patients treated conservatively, ${ }^{12}{ }^{19-20}$ although prominent interfascicular fibrosis was probably present in these cases also.

This raises the question what is the pathophysiological significance of the epineural and perineural fibrosis, which is the prime target of interfascicular neurolysis? As shown by Change et al $^{21}$ epifibrosis and perifibrosis of the ulnar nerve is a frequent finding in persons without symptoms or signs of ulnar nerve palsy. It was present in nearly $50 \%$ of their 400 nerves at autopsy, in $20 \%$ reaching moderate to severe degrees. Neary et $a l^{22}$ in their histomorphometric autopsy study of 12 ulnar nerves from patients without neuropathy, noted that the connective tissue changes "did not appear to be related to the presence or absence of nerve fibre damage". In rabbit nerves subjected to repeated crush injuries, Thomas $^{23}$ observed an increased number of fibroblasts and an enlargement of the endoneurial space mainly containing fibrillar connective tissue in addition to a proliferation of Schwann cells. Repeated local tourniquet application to rat nerves resulted in a reparative increase of the interfascicular area independent of the development of onion bulbs. ${ }^{24}$ On the other hand, chronic entrapment of growing rabbit nerves by unyielding tubes led to local demyelination with slowing of the nerve conduction without any increase of the interfascicular area. ${ }^{15}$

These observations suggest that the interfascicular fibrosis is a response to repeated external trauma which may or may not be accompanied by degenerative changes in the nerve fibres. ${ }^{16}{ }^{25}$ There is little to suggest that perifibrosis per se plays a significant role in nerve fibre degeneration as long as the nerve is not subjected to external compression. Hence, the negative results of interfascicular neurolysis are hardly surprising, and it appears to us more relevant to emphasise the obvious risk of causing further damage to the nerve inherent in the technique. Postoperative paraesthesia is, moreover, an unpleasant and seemingly unavoidable complication of microsurgical treatment of ulnar palsy, and for these reasons we suggest that the technique be abandoned.

\section{References}

1 deJesus PV, Steiner JC. Spontaneous recovery of ulnar neuropathy at the elbow. Electromyogr clinl Neurophysiol 1976; 16:239-48.

2 Millesi $H$, Ganglberger J, Berger A. The interfascicular nerve-grafting of the median and ulnar nerves. J Bone Joint Surg 1972; 54A:727-50.

3 Samii M. Die operative Wiederherstellung verletzter Nerven. Langenbecks Arch Chir 1972; 332:355-62.

4 Brown HA. Internal neurolysis in the treatment of peripheral nerve injuries. Clin Neurosurg 1970; 17:99-110.

5 Curtis RM, Eversmann Jr WW. Internal neurolysis as an adjunct to the treatment of the carpaltunnel syndrome. J Bone Joint Surg 1973; 55A: $733-40$.

6 Elies W, Driesen W. Ergebnisse der operativen Behandlung peripherer Nervenverletzungen durch interfasciculäre autologe Nerventransplantation oder innere Neurolyse. Chirurg 1974; 45:556-60.

7 Benini A. Die intraneurale Neurolyse. Indication, Technik, Ergebnisse. Ther Umsch 1975; 32:440-5.

8 Dolenc V, Trontelj JV. Pressure neuropathies-the need for microsurgical approach. In: Canal N, Pozza P, eds. The Peripheral Neuropathy. North Holland, Elsevier, 1978; 367-72.

9 Castellanos F, Guillen R, Castilla JM, JiminezCasteelanos J. Microsurgical treatment of the entrapment neuropathies of the upper limb. In: Canal N, Pozza P, eds. The Peripheral Neuropathy. North Holland: Elsevier, 1978; 373-8.

10 McGowan AJ. The results of transposition of the ulnar nerve for traumatic ulnar neuritis. $J$ Bone Joint Surg 1950; 32B:293-301.

11 Payan J. Electrophysiological localisation of ulnar nerve lesions. J Neurol Neurosurg Psychiatry 1965; 32:208-20.

12 Payan J. Anterior transposition of the ulnar nerve: An electrophysiological study. J Neurol Neurosurg Psychiatry 1970; 33:157-65.

13 Wagner AL, Buchthal F. Motor and sensory conduction in infancy and childhood. Reappraisal. Dev Med Child Neurol 1972; 14:189216.

14 Rosenfalck P, Rosenfalck A. Electromyography - Sensory and motor conduction. Findings in normal subjects. Laboratory of Clinical Neuro- 
physiology. Rigshospitalets forlag: Copenhagen, 1975.

15 Aguayo A, Nair CPV, Midgley R. Experimental progressive compression neuropathy in the rabbit. Histological and electrophysiological studies. Arch Neurol 1971; 24:358-64.

16 Thomas PK, Olsson Y. Microscopic anatomy and function of the connective tissue components of peripheral nerve. In: Dyck PJ, Thomas PK, Lambert EH, eds. Peripheral Neuropathy. Philadelphia: Saunders, 1975; 168-89.

17 Lugnegård H, Walheim, G, Wennberg A. Operative treatment of ulnar neuropathy in the elbow region. A clinical and electrophysiological study. Acta orthop Scand 1977; 48:168-76.

18 Hongell A, Mattsson HS. Neurographic studies before, after, and during operation for median nerve compression in the carpal tunnel. Scand J Plast Reconstr Surg 1971; 5:103-9.

19 Assmus H, Klug N, Kontopoulos B, Penholz H. Das Sulcus Ulnaris Syndrom. Electroneurographische Untersuchungen und Behandlungsergebnisse. J Neurol 1974; 208:109-22.
20 Eisen A, Donan J. The mild cubital tunnel syndrome. Its natural history and indications for surgical intervention. Neurology 1974; 24:608-13.

21 Chang KSF, Low WD, Chan ST, Chuang A, Poon KT. Enlargement of the ulnar nerve behind the medial epicondyle. Anat Rec 1963; 145: 149-55.

22 Neary D, Ochoa J, Gilliatt RW. Sub-clinical entrapment neuropathy in man. $J$ Neurol Sci $1975 ; 24: 283-98$.

23 Thomas PK. The cellular response to nerve injury. J Anat 1970; 106:463-70.

24 Dyck PJ. Experimental hypertrophic neuropathy. Pathogenesis of onion-bulb formations produced by repeated tourniquet applications. Arch Neurol 1969; 21:73-95.

25 Sunderland $\mathrm{S}$. The connective tissue of peripheral nerves. Brain 1965; 88:841-54.

26 Slomic A, Rosenfalck A, Buchthal F. Electrical and mechanical responses of normal and myasthenic muscle. Brain Research 1968; 10:1-78. 